\title{
METAL HYDRIDE HYDROGEN COMPRESSION: RECENT ADVANCES AND FUTURE PROSPECTS
}

\author{
Volodymyr A. Yartys ${ }^{\left.1,2^{*}\right)}$ \\ (1) Institute for Energy Technology, P.O. Box 40, Kjeller NO-2027, Norway \\ (2) Norwegian University of Science and Technology, Trondheim, No-7491, Norway \\ volodymyr.yartys@ife.no
}

Mykhaylo Lototskyy ${ }^{3}$ and Vladimir Linkov ${ }^{3}$

(3) South African Institute for Advanced Materials Chemistry, University of the Western Cape, Robert Sobukwe Road, Private Bag X17, Bellville 7535, South Africa mlototskyy@uwc.ac.za; vlinkov@uwc.ac.za

David Grant ${ }^{4}$ and Alastair Stuart ${ }^{4}$

(4) Faculty of Engineering, University of Nottingham, Nottingham, NG7 2RD, UK

David.Grant@nottingham.ac.uk; Alastair.Stuart@nottingham.ac.uk

Jon Eriksen ${ }^{5}$ and Roman Denys ${ }^{5}$

(5) HYSTORSYS AS, P.O. Box 45, NO-2027 Kjeller, Norway

jon.eriksen@hystorsys.no; roman.denys@hystorsys.no

Robert C. Bowman, Jr. 6

(6) Oak Ridge National Laboratory, P.O. Box 2008, Oak Ridge, TN 37831, USA rcbjr1967@gmail.com

${ }^{*}$ Corresponding author. E-mail: volodymyr.yartys@ife.no. Tel. +47 45422065. 


\section{ABSTRACT OF THE MANUSCRIPT}

Metal hydride (MH) thermal sorption compression is one of the more important applications of the metal hydrides. The present paper reviews recent advances in the field based on the analysis of the fundamental principles of this technology. The performances when boosting hydrogen pressure, along with two- and three-step compression units are analyzed. The paper includes also a theoretical modeling of a two-stage compressor aimed at both describing the performance of the experimentally studied systems, but, also, on their optimization and design of more advanced $\mathrm{MH}$ compressors. Business developments in the field are reviewed for the Norwegian company HYSTORSYS AS and the South African Institute for Advanced Materials Chemistry. Finally, future prospects are outlined presenting the role of the metal hydride compression in the overall development of the hydrogen driven energy systems. The work is based on the analysis of the development of the technology in Europe, USA and South Africa. 


\section{INTRODUCTION}

The present work is aimed on a review of the recent progress made in the past years, particularly in the framework of the International Energy Agency Task 32 Hydrogen Based Energy Storage, in the area of the thermally driven systems for storage and compression of hydrogen gas utilizing metal hydrides.

Metal hydride $(\mathrm{MH})$ hydrogen compression utilizes a reversible heat-driven interaction of a hydride-forming metal, alloy or intermetallic compound with hydrogen gas to form $\mathrm{MH}$ and is considered as a promising application for hydrogen energy systems. This technology, which initially arose in early 1970s, still offers a very good alternative to both conventional (mechanical) and newly developed (electrochemical, ionic liquid pistons) methods of hydrogen compression. The advantages of $\mathrm{MH}$ compression include simplicity in design and operation, absence of moving parts, compactness, safety and reliability, and the possibility to utilize waste industrial heat instead of locally generated or purchased electricity for much, if not all, of the heating of the $\mathrm{MH}$ containers.

Use of the waste industrial heat is a major winning argument for $\mathrm{MH}$ compression by allowing dramatic decreases in operational costs.

A state-of-the-art review on metal hydride hydrogen compression technology was recently published by Lototskyy, Yartys et al. [1]. The studies reported after publishing this review were mainly focused on the development and characterisation of metal hydride materials for hydrogen compression [2-5], modelling of the $\mathrm{MH}$ compression systems [6,7], components and system developments [7-10] including a review by Bhuiya et. al on non-hydrogen storage $\mathrm{MH}$ applications [10]. Other applications for $\mathrm{MH}$ compressors described since Reference 1 was published include generating high pressure for in situ powder XRD studies [11] and MH driven actuators [12].

This article outlines the critical components of the $\mathrm{MH}$ hydrogen compression technology with a focus on the phase equilibria in the metal - hydrogen systems and modelling of the heat-and mass transfer processes in the coupled MH beds. The authors also present some recent developments of industrial-scale metal hydride hydrogen compressors at HYSTORSYS AS / Norway and SAIAMC / UWC / South Africa. Finally, we briefly describe some additional recently proposed applications for the $\mathrm{MH}$ hydrogen compression technology.

\section{GENERAL CONCEPT OF THE MH COMPRESSION}

Metal hydride hydrogen compression, uses a reversible heat-driven interaction of a hydride-forming metal / alloy, or intermetallic compound with hydrogen gas, to form a metal hydride:

$$
\mathbf{M}(\mathbf{s})+\mathbf{x} / \mathbf{2} \mathbf{H}_{2}(\mathrm{~g}) \underset{\text { desorption }}{\stackrel{\text { absorption }}{\rightleftarrows}} \mathrm{MH}_{\mathbf{x}}(\mathrm{s})+Q
$$


where $\mathrm{M}$ denotes the hydride forming metal / alloy / intermetallic compound, (s) and (g) relate to the solid and gas phases, respectively. The direct forward process results in an exothermic formation of the metal hydride / hydrogen absorption and is accompanied by the release of heat, $Q$ equal to the absolute value of the hydrogenation enthalpy, $|\Delta H|$. The reverse process results in endothermic hydride decomposition / hydrogen desorption, requiring supply of approximately the same amount of heat at a higher operating temperature.

Equilibrium of the reaction (1) is characterised by an interrelation between hydrogen pressure $(P)$, concentration of hydrogen in the solid $(C)$ and temperature $(T)$. This relation (PCT-diagram) is the characteristic feature of a specific hydride-forming material determining thermodynamics of its interaction with gaseous hydrogen.

At low hydrogen concentrations $(0 \leq C<a)$ hydrogen atoms form an interstitial solid solution in the metal matrix ( $\alpha$-phase) with $\mathrm{C}(\mathrm{H}) \sim \sqrt{P\left(\mathrm{H}_{2}\right)}$ according to a Henry-Sieverts law. When the value of $\mathrm{C}$ exceeds concentration of the saturated solid solution ( $a$ ), a precipitation of the hydride ( $\beta$-phase with hydrogen concentration $b>a$ ) nucleates, and the system ideally behaves according to the first order phase transition law taking place at a constant hydrogen pressure, $P=P_{P}(a \leq C \leq b)$. This pressure is identified as a plateau pressure in the diagrams of the metal-hydrogen systems. Further increase in hydrogen concentration is again accompanied by the pressure increase corresponding to the formation of an $\mathrm{H}$ solid solution in the $\beta$-phase. When the concentration approaches a certain maximum value $\left(C \rightarrow C_{\max }\right)$ corresponding to the maximum hydrogen capacity of the material (i.e., the number of hydrogen atoms fill all interstitial sites available for the insertion of $\mathrm{H}$ atoms) the equilibrium pressure exhibits an asymptotic increase, $P \rightarrow \infty$.

The plateau width, $(b-a)$, is often considered as a reversible hydrogen capacity of the material, and the equilibrium of reaction (1) in the plateau region is described by a Van't Hoff equation:

$$
\ln \left(\frac{P_{P}}{P^{0}}\right)=-\frac{\Delta S^{0}}{R}+\frac{\Delta H^{0}}{R T} \quad ;
$$

where $P^{0}=1 \mathrm{~atm}=1.013 \mathrm{bar}, \Delta S^{0}$ and $\Delta H^{0}$ are the standard entropy and enthalpy of hydride formation respectively, $R$ is the universal gas constant.

Since the plateau pressure, $P_{P}$, increases exponentially with the temperature (see Fig. 1), the lowtemperature $\left(T=T_{L}\right) \mathrm{H}$ absorption at $P_{\mathrm{H}_{2}}>P_{P}\left(T_{L}\right)=P_{L}$ takes place at a lower hydrogen pressure, and the hightemperature $\left(T=T_{H}\right) \mathrm{H}$ desorption $\left(P_{\mathrm{H}_{2}}<P_{P}\left(T_{H}\right)=P_{H}\right)$ occurs at a higher pressure, similar to the suction and discharge processes in a mechanical compressor.

Fig. 1 illustrates a general concept of the $\mathrm{MH}$ hydrogen compression realized with the use of intermetallic alloys $\mathrm{La}_{0.85} \mathrm{Ce}_{0.15} \mathrm{Ni}_{5}(1)$ and $\mathrm{C} 14-\mathrm{Ti}_{0.65} \mathrm{Zr} \mathrm{r}_{0.35}(\mathrm{Mn}, \mathrm{Cr}, \mathrm{Fe}, \mathrm{Ni})_{2}(2)$ applied by IFE and SAIAMC / UWC in their 
developments of the thermally driven metal hydride hydrogen compressors. At $T_{L}=20^{\circ} \mathrm{C}$ the hydrogenated alloys have plateau pressures of $P_{L}(1)=3.5 \mathrm{~atm}$ and $P_{L}(2)=20 \mathrm{~atm}$, respectively, while at $T_{H}=130{ }^{\circ} \mathrm{C}$ the plateau pressures are $P_{H}(1)=45.5 \mathrm{~atm}$ and $P_{H}(2)=261 \mathrm{~atm}$ yielding the compression ratios of about $13 \mathrm{in}$ both cases.

In contrast, by application of a two-stage operation it is possible to achieve $\mathrm{H}_{2}$ compression from $P_{L}(1)=3.5$ atm to $P_{H}(2)=261 \mathrm{~atm}$ (compression ratio 74.6 ) in the same temperature range. In such a process, the medium-pressure hydrogen at $P_{L}(2) \leq P_{M} \leq P_{H}(1)$ is desorbed from the $A B_{5}$-type hydride (1) at the temperature $T=T_{H}$ (process $\mathrm{AB}$ ), and further absorbed in the $\mathrm{AB}_{2}$-type alloy (2) at $T_{L} \leq T \leq T_{M}$ (process $\mathrm{BC}$ ) followed by the desorption at $T=T_{H}$ and $P=P_{H}(2$; process $C D)$.

\section{Fig. 1 PLEASE, INSERT HERE}

The dependencies 1 and 2 in Fig. 1 were built on the basis of the experimental PCT data for both alloys further processed by modeling [13] with an average calculation error in $\mathrm{H}$ concentrations below $2 \mathrm{NL} / \mathrm{kg}$. At the same time, they still represent idealized performance of the $\mathrm{MH}$ compressor, without taking into account hysteresis and cycle productivity.

More precise thermodynamic estimations can be done by considering the whole hydrogen absorption and desorption isotherms (Fig. 2). The isotherms for $\mathrm{La}_{0.85} \mathrm{Ce}_{0.15} \mathrm{Ni}_{5}$ (stage 1 ) and $\mathrm{C} 14-\mathrm{Ti}_{0.65} \mathrm{Zr}_{0.35}(\mathrm{Mn}, \mathrm{Cr}, \mathrm{Fe}, \mathrm{Ni})_{2}$ (stage 2) were also built using the model [13] with the parameters obtained by the refinement of the experimental PCT data.

As it can be seen from Fig. 2, the two-stage hydrogen compression from $P_{L}=10$ bar to $P_{H}=200$ bar (overall compression ratio 20 ) in temperature range from $T_{L}=20^{\circ} \mathrm{C}$ to $T_{H}=130^{\circ} \mathrm{C}$ involves the following processes:

- $\quad$ AB: Hydrogen absorption in the stage $1 \mathrm{MH}$ material at $P_{L}$ and $T_{L}$;

- $\quad \mathrm{BC}$ : Hydrogen desorption from the stage $1 \mathrm{MH}$ at $T=T_{H}$ and an intermediate pressure, $P_{M}$;

- CD: Hydrogen absorption in the stage $2 \mathrm{MH}$ at $P_{M}$ and $T_{L}$;

- DEF: Hydrogen desorption from the stage $2 \mathrm{MH}$ at $T_{H}$ and $P_{H}$.

Each process is accompanied by the transfer of hydrogen, and the overall process cycle productivity will be determined by the minimum amount of the transferred hydrogen $\left(\Delta C_{H}\right)$ in the course of two-stage $\mathrm{H}_{2}$ compression process $A B C D E F$. As it can be seen from Fig. 2, this minimum amount (process $D E ; \Delta C_{H}=75$ $\mathrm{NL} / \mathrm{kg}$ at $P_{M}=40 \mathrm{~atm}$ ), as a rule, is determined by under-saturation of the stage 2 material during $\mathrm{H}_{2}$ transfer between the first and the second stage of the $\mathrm{MH}$ compressor (process $\mathrm{CD}$ ). This feature was observed experimentally in [14] in the course of the tests of 10-200 bar MH hydrogen compressor at SAIAMC / UWC which utilized the same hydride materials for the stages 1 and 2.

Fig. 2 PLEASE, INSERT HERE 
In summary, accurate thermodynamic estimation of hydrogen compression performance of $\mathrm{MH}$ materials, including process cycle productivity $\left(\Delta C_{H}\right)$ at the given suction $\left(P_{L}\right)$ and discharge $\left(P_{H}\right)$ pressures and cooling $\left(T_{L}\right)$ and heating $\left(T_{H}\right)$ temperatures is especially critical for the multistage $\mathrm{H}_{2}$ compression and becomes possible when complete isotherms of hydrogen absorption at $T_{L}$ and hydrogen desorption at $T_{H}$, accounting plateau slope and hysteresis, are taken into consideration. This assessment can be done by the fitting the available experimental PCT data using suitable models of phase equilibria in metal - hydrogen systems. We note that the model also has to take into account the features of $\mathrm{H}-\mathrm{M}$ phase diagram since in wide range of the operating temperatures $\left(T_{L} \ldots T_{H}\right)$ a noticeable change of the concentrations $(a, b)$ limiting the twophase $(\alpha+\beta)$ concentration region of the pressure - composition isotherms is observed (see Fig. 2 ).

During the developments of thermally driven metal hydride hydrogen compressors at IFE, HYSTORSYS AS and SAIAMC / UWC, the authors (VY, ML, VL) mainly used the model [13] which takes these features into account by assuming $\mathrm{H}$ atoms in the solid as a Van der Waals lattice gas and Gaussian distribution of the plateau pressures. In addition, the model uses Kierstead's approach [15] in order to simulate pressure composition isotherms when there are several plateau segments. The latter feature is very useful for the estimation of hydrogen compression performances of the "multiplateau" systems, both for some intermetallics (e.g., TiFe), and, also for the mixtures of different $\mathrm{MH}$ materials.

Fig. 3 presents calculated PCT diagram of $\mathrm{MH}$ material on the basis of $\mathrm{C}^{14}-\mathrm{Ti}_{0.65} \mathrm{Zr}_{0.35}(\mathrm{Mn}, \mathrm{Cr}, \mathrm{Fe}, \mathrm{Ni})_{2}$ used for $\mathrm{H}_{2}$ compression to 200 bar and higher at the heating temperatures below $130-150{ }^{\circ} \mathrm{C}$. The material also contains 10 wt.\% La ${ }_{0.8} \mathrm{Ce}_{0.2} \mathrm{Ni}_{5}$ added for the improvement of the activation performances of the $\mathrm{AB}_{2}$-type intermetallic. The fitting parameters of the model [13] obtained by the refinement of the separately taken PCT data for the $A B_{2}$ - and $A B_{5}$-type alloys allowed us to re-construct the PCT diagram of the mixture that, in turn, improved accuracy of modelling the performances of the corresponding compression elements.

Fig. 3 PLEASE, INSERT HERE

\section{PROOF OF CONCEPT: A SINGLE STEP 350 L / 200 BAR MH HYDROGEN STORAGE AND COMPRESSION UNIT USING $\mathrm{AB}_{5}$ TYPE ALLOY}

The first developments of $\mathrm{MH}$ units combining hydrogen storage and compression occurred in the late 1960s during the pioneer work by Wiswall and Reilly [16]. Similar solutions were developed in the Russian Federal Nuclear Centre (VNIIEF), disclosed in late 1990s [17]. The latter are rather impressive: vanadium hydride was heated to $500^{\circ} \mathrm{C}$ [17] generating hydrogen pressures as high as $5 \mathrm{kbar}$. A significant contribution to the art was also done in 1980-90s by the group from Institute of Mechanical Engineering Problems / Academy of Science of Ukraine (IPMach; see[18]). One of the important features of these developments was in the original engineering solution allowing to control the output hydrogen pressure by introducing a feedback between its value and the heating / cooling power supplied to the MH bed.

All the solutions provide hydrogen storage in $\mathrm{MH}$ and its periodic supply at higher pressure to a consumer. Since the main attention here was mainly paid to the system layout, without optimization of the $\mathrm{MH}$ material for the application, the units had low productivities and efficiencies, and, as a rule, were 
characterised by too high temperatures necessary to provide the required output pressure. For example, the mentioned developments by IPMach, where $\mathrm{LaNi}_{5} \mathrm{H}_{\mathrm{x}}$ was mainly used, required temperatures 250 to $300{ }^{\circ} \mathrm{C}$ to reach the output pressures 100 to 150 bar. Also, in the time when the developments were implemented, the lack of digital electronics did not allow to completely realize all the advantages of the proposed engineering solutions, especially those ones which concerned the automated pressure control.

We consider the small-scale ( $\sim 100$ litres $\mathrm{H}_{2}$ ) units for hydrogen storage and compression as convenient facilities for the testing of $\mathrm{MH}$ materials for hydrogen compression at the conditions maximally close to ones for the application. Moreover, such units can be used as efficient laboratory equipment providing safe and simple in operation supplies of high-pressure hydrogen gas to experimental facilities.

This development has arisen more recently as a result of activities of hydrogen storage group at the Institute for Energy Technology, Department of Energy Systems. These activities are devoted to the implementation of metal hydrides for high-pressure hydrogen compression and were started in 2003. Some preliminary results, including the development of the experimental prototype of 200 litres / 160 bar $\mathrm{H}$ storage and compression unit (with the participation of the Institute for Problems of Materials Science, National Academy of Science of Ukraine) were published [19]. Finally, the 350 litres / 200 bar unit being described in this section uses an $A B_{5}$ hydrogen storage alloy in combination with electric heating and air cooling. This has been built and experimentally studied, to specify dependencies between generated pressure and $\mathrm{MH}$ bed temperature, as well as to estimate the discharge dynamic performances. Also, an important result was in the creation of the supply system providing our experimental facilities with hydrogen at high pressure, with the possibility to precisely set its value.

$A B_{5}$ alloys, where $A$ is rare earth metal and $B$ is mainly nickel, are the most frequently used materials for $\mathrm{MH}$ applications. Their main advantages are: low sensitivity to poisoning by impurities, easy activation and fast $H$ sorption - desorption kinetics. The broad range of PCT versatility and tunability is evident for $A_{5}$, with the room temperature plateau pressure variable over three orders of magnitude depending on the composition [20]. On the other hand, many $A B_{5}$ alloys are subject to degradation via disproportionation reactions during extended cycling to elevated temperatures as described in Reference 1. It is also known that substitution of Al or $\mathrm{Sn}$ for a portion of the $\mathrm{Ni}$ results in greatly enhanced stabilities while heating treatments at low pressure and temperatures circa $400{ }^{\circ} \mathrm{C}$ produce nearly $100 \%$ recovery of the hydrogen storage performances [1].

Fig. 4a shows our estimations of the formation enthalpies of intermetallic hydrides $\mathrm{La}_{1-\mathrm{x}} \mathrm{Ce}_{\mathrm{x}} \mathrm{Ni}_{5} \mathrm{H}_{\mathrm{y}}$ based on the available reference data [21]. The corresponding calculation of hydrogen equilibrium pressures (Fig. $4 \mathrm{~b}$ ) assuming $\Delta S^{0}=-110 \mathrm{~J} /\left(\right.$ mole H$_{2} \cdot \mathrm{K}$ ) shows that at the composition of the intermetallic corresponding to the formula $\mathrm{La}_{0.85} \mathrm{Ce}_{0.15} \mathrm{Ni}_{5}$ the pressures above 200 bar can be generated at the temperatures below $180^{\circ} \mathrm{C}$, and at room temperature the equilibrium pressure is below 10 bar. It satisfies to our primary objective as to pressure - temperature ranges for $\mathrm{MH}$ hydrogen compression. At the same time, the cerium contents in the alloy is low enough that allows to avoid such negative features of Ce-rich intermetallics as lower $\mathrm{H}$ storage capacity and increased hysteresis.

Fig. 4. PLEASE, INSERT HERE

The alloy of the specified composition $\mathrm{La}_{0.85} \mathrm{Ce}_{0.15} \mathrm{Ni}_{5}$ which is indicated by dashed line in Fig. 4, was purchased from Labtech Int. Co. Ltd., supplied in the powdered form. 
According to XRD analysis of different batches of the starting and hydrogenated ${ }^{1}$ alloy from various suppliers, both comprised the $\mathrm{CaCu}_{5}$-type single or major ${ }^{2}$ phase with lattice periods varying within $a=4.99-$ $5.02 \AA, c=3.995-3.999 \AA$ for the parent intermetallic and volume increase upon hydrogenation, $\Delta \mathrm{V} / \mathrm{V}_{0}$ between 24 and $24.5 \%$.

Fig. 5 shows PCT diagram of hydrogen absorption and desorption by the $\mathrm{La}_{0.85} \mathrm{Ce}_{0.15} \mathrm{Ni}_{5} \mathrm{H}$ storage alloy. The experimental data (points) were fitted using our model of phase equilibria in metal - hydrogen systems [13] the calculated PCT diagram is presented as the wire-frame surface. The modelling / fitting procedure also used the equilibrium data obtained during the tests of the unit containing the same $\mathrm{H}$ storage alloy. For simplicity we did not take into account hysteresis, using both absorption and desorption data.

According preliminary PCT studies, the hysteresis energy losses, $R T \ln \left(P_{A} / P_{D}\right)$, were less than 900 $\mathrm{J} /$ mole $\mathrm{H}_{2}$ that corresponds to $\left(P_{A} / P_{D}\right) \approx 1.4$ at room temperature, or $\left(\frac{T_{A}-T_{D}}{T_{D}}\right)<0.04$. We think that these differences are not so significant for our case, since other uncertainties (e.g. introduced by temperature distribution in the $\mathrm{MH}$ bed) can result in a bigger contribution into the observed PCT data.

The calculated pressure - temperature dependencies for $\mathrm{H}_{2}$ desorption from the hydrogenated $\mathrm{La}_{0.85} \mathrm{Ce}_{0.15} \mathrm{Ni}_{5}$ are shown in Fig. 6 . It is seen that at the higher saturations of the alloy with hydrogen (>60\% of the maximum hydrogen storage capacity) rather high pressures ( $>150$ bar) can be generated by the heating of the material to the temperatures up to $200^{\circ} \mathrm{C}$.

Fig. 5 PLEASE, INSERT HERE

Fig. 6 PLEASE INSERT HERE

The data presented in Fig. 5,6 confirm our estimations (Fig. 4): the plateau pressure at rather low temperature of $150^{\circ} \mathrm{C}$ exceeds 100 bar, and at ambient temperature $\left(T=30^{\circ} \mathrm{C}\right)$ it is between 10 and 20 bar, that is acceptable for the application. The maximum hydrogen sorption capacity approaches to $6.0 \mathrm{H} / \mathrm{AB}_{5}$ corresponding to 155 litres $\mathrm{H}_{2}$ STP per $1 \mathrm{~kg}$. The reversible $\mathrm{H}$ storage capacity, as it can be seen from Fig. 5 , is more than $90 \%$ of the corresponding maximum value. Both absorption and desorption of hydrogen at the experimental conditions were fast: more than $90 \%$ of hydrogen is absorbed / desorbed in less than 1015 minutes.

A general view and schematics of the hydrogen storage and supply system are presented in Fig. 7. The $\mathrm{MH}$ container (1) is fixed to the perforated horizontal shelf of a cabinet where the whole system (gas

\footnotetext{
${ }^{1}$ Before taking XRD of the hydrogenated samples, the hydrides were stabilised by the exposition on air at $T=77 \mathrm{~K}$; the patterns showed presence of two-phases including intermetallic hydride with increased unit cell volume, and $\alpha$-solid solution with the lattice periods close to those of the starting alloy.

${ }^{2}$ In some samples impurity of $\mathrm{Ni}(<0.5 \mathrm{wt} . \%)$ was observed
} 
communications and electronics) is assembled. The shut-off diaphragm valves (2) installed on the front panel of the cabinet provide manually operated connection of the container's gas manifold with $\mathrm{H}_{2}$ discharge or charge lines whose ports ( 5 and 6 , respectively) are installed on the rear panel. For overpressure protection, the gas manifold is also connected with a port of venting line (7), via relief valve (3) adjusted to a cracking pressure of 210 bar. The gas manifold of the container (1) is also connected to a 210 bar pressure sensor (4; Omega PX482A-3KSI, 4-20 mADC output). All the connections are performed using $1 / 4$ " OD stainless steel tubing and the corresponding Swagelok tube fittings.

Hydrogen supply at higher pressures is provided by heating the $\mathrm{MH}$ bed in the container (1), by cartridge electric heater (1a; 230 VAC, $800 \mathrm{~W}$ ) axially placed in the container. Heat dissipation is provided by external air cooling with two fans $(12 ; 230 \mathrm{VAC}, 28 \mathrm{~W}$ each) placed under the perforated shelf.

\section{Fig. 7 PLEASE, INSERT HERE}

A simplified control diagram of the system is presented in Fig. 7d. The main output of the control circuit is the electric power supplied to the heater (1a) of the MH container (1). The control circuit has two inputs, viz. the temperature in the container measured by the thermocouple ( $1 \mathrm{~b}$; K-type) and the hydrogen pressure measured by the pressure sensor (4; Omega PX482A-3KSI). The last parameter provides the main feedback signal (DC current proportional to hydrogen pressure) monitored by the display unit (10; Omega DP24-E-230) and simultaneously connected to the input of the PID controller (8; Eurotherm 2408). The output of the controller (8) is connected to the input of a power amplifier (11; TF10a) via ON / OFF controller (9; Eurotherm 2132) whose input is connected to the thermocouple (1b). The output of the power amplifier (11) is connected to the heater (1a). In turn, the auxiliary ON / OFF output (alarm relay) of the PID controller (8) provides switching cooling fans (12) on and off.

During the operation the PID controller (8), together with the power amplifier (11), provides power supply to the heater (1a) of the $\mathrm{MH}$ container (1). Heating the $\mathrm{MH}$ container stimulates hydrogen desorption from the $\mathrm{MH}$ at a higher pressure which is monitored by the sensor (4). When the pressure approaches the setpoint of the PID controller (8), it reduces the power supplied to the heater (1a), similarly to its standard operation in temperature control mode. If pressure overshoot takes place, the alarm relay of the PID controller (8) switches the fans (12) on, resulting in the cooling of the MH container and corresponding decrease of the hydrogen pressure.

The setpoint of the controller (9) all the time is equal to maximum allowed temperature of the $\mathrm{MH}$ container $\left(200^{\circ} \mathrm{C}\right)$. When the temperature monitored by the thermocouple (1b) reaches this value (it occurs at the end of discharge where hydrogen equilibrium pressures above depleted $\mathrm{MH}$ can be reached only at higher temperatures), power supply to the heater (1a) is switched off, the heating is resumed when the temperature decreases below $200^{\circ} \mathrm{C}$.

Fig. 8 presents assembly drawing of the MH container used in the system. The powdered MH bed is placed in the space formed by stainless steel bottom flange (1), external tubular shell (2), top flange (3), and the 
internal heat exchanger (4). The latter is formed by the stainless steel core tube (outer diameter $25.4 \mathrm{~mm}$, wall thickness $2.64 \mathrm{~mm}$ ) and aluminium 1060 fins (height $15.8 \mathrm{~mm}$, thickness $0.4 \mathrm{~mm}$, pitch $2.3 \mathrm{~mm}$ ). The inner space (1a) of the heat exchanger (4) is adjusted for the tight fit of the cartridge-type electric heater. To reduce thermally-induced stresses, only one end of core tube of the heat exchanger is fixed rigidly (welded) to the flange (1); the other end is plugged and left in the non-fixed position. The top flange (3) of the container is equipped with the male VCR-type metal gasket face seal fittings for input / output of hydrogen gas ( $3 \mathrm{a}$ ) and loading / unloading the MH powder (3b). The gas fitting ( $3 \mathrm{a})$ is connected with the tubular porous stainless steel filter (5), pore size of $5 \mu$. The top flange (1) of the container has the fitting where stainless steel shield of the K-type thermocouple (6) is firmly fixed. The junction of the thermocouple (6) is located in the middle of the MH bed, as respect to both its length and thickness.

The design of the $\mathrm{MH}$ container (Fig. 8) allows its prolonged operation at gas pressures up to 200 bar and temperatures up to $200^{\circ} \mathrm{C}$. In addition, after its assembly the container has successfully passed the test at gas pressure (argon) up to 300 bar and temperature up to $250^{\circ} \mathrm{C}$; test duration at the most extreme conditions ( $300 \mathrm{bar} / 250^{\circ} \mathrm{C}$ ) was about 10 minutes. The test was performed by RAUFOSS Fuel Systems ASA, with the participation of the authors (ML, VY; test report RAFS-00205, 12.05.2006).

The internal volume of the $\mathrm{MH}$ container is of $640 \mathrm{~cm}^{3}$ that corresponds to the total amount of the $\mathrm{H}_{2}$ storage alloy of $2.234 \mathrm{~kg}$, at the filling density of $3.5 \mathrm{~g} / \mathrm{cm}^{3}$, or $\sim 53 \%$ of the density of the hydrogenated alloy, in accordance to the upper limit of safe packing fraction $(<61 \%)$ for $A B_{5}$-type hydrides reported in the literature [22]. At the same time, such an amount of the alloy provides the specified $\mathrm{H}_{2}$ storage capacity of $350 \mathrm{NL} \mathrm{H}_{2}$.

Fig. 8 PLEASE, INSERT HERE

Under testing conditions the setpoint after its increase was reached in 10 minutes, and in 20 minutes the pressure stabilisation mode was established. The maximum overshoot did not exceed 5 bar. After decreasing the setpoint, it was reached in 15 minutes, and the time of pressure stabilisation was about 30 minutes. Both the reproducibility of the pressure setpoint and stability of its maintaining were better than $0.05 \%$. As it can be seen from Fig. 9, generation of hydrogen pressure in the range 50 to 200 bar requires moderate temperatures, 100 to $180^{\circ} \mathrm{C}$.

Fig. 9 PLEASE, INSERT HERE

The maximum output flow rate determined in the course of discharge of the unit to the mediumpressure Sieverts' setup (total discharge volume about 3 litres) was about $10 \mathrm{l} / \mathrm{min}$ (Fig. 10). At $\mathrm{H} / \mathrm{AB}_{5}>2.5$ and $\mathrm{P}<40$ bar the rate of the discharge does not significantly depend on pressure or on hydrogen concentration in $\mathrm{MH}$; while at lower $\mathrm{H}$ concentration the discharge rate is proportional to it. 
Fig. 10 PLEASE, INSERT HERE

In our opinion based on the application of the analysis of performances of $\mathrm{MH}$ compressors [1] to the present development, the main contribution into the limitation of the discharge dynamics is introduced by a too high heat capacity of the empty $\mathrm{MH}$ container whose weight $(\sim 10 \mathrm{~kg})$ exceeds the weight of the $\mathrm{MH}$ material by more than 4 times. It is also confirmed by the slow dynamics of charging the unit, as well as by its slow cooling / decreasing the pressure, after turning the unit off (see the last descending segment of the P-T curves in Fig. 9). To radically improve the dynamic performances of high-pressure MH TSC, it is necessary to find the novel engineering solutions of its main component part, $\mathrm{MH}$ container which should combine the high enough mechanical strength with minimal heat capacity, i.e. minimal material consumption and weight.

Results of testing of the MH hydrogen storage and compression unit have confirmed our supposition that such an apparatus can be very efficient and convenient in operation laboratory equipment providing experimental facilities with hydrogen supplied at pre-defined higher pressures. To reveal its potential on the market of laboratory equipment, we finally made a brief economic analysis based on real costs for the used standard components, as well as on the estimations of workload / labor costs necessary for the production of the unit.

The total manufacture costs are estimated as 43 to 45 thousands Norwegian crowns (NOK) that is the same order as the price of ordinary laboratory equipment, such as thermostats, vacuum systems, etc.

The main categories of the costs are shown in Fig. 11. In contrast to other applications of $\mathrm{MH}$, the presented one is characterized by rather low fraction of $\mathrm{MH}$ material in the total cost, $2 \%$ against $15-50 \%$ for $\mathrm{MH}$ hydrogen storage units [23]. It does mean that for the selection of $\mathrm{MH}$ material for this application good kinetics and durability performances should be main criteria, and it is not so critical to optimise its cost. The most expensive categories ( $35 \%$ each) are electronics and labor. Both, especially the latter, are subjects for the optimization, by optimizing system layout and non-standard components (first of all, $\mathrm{MH}$ container) and improving their making technology.

Fig. 11 PLEASE, INSERT HERE

In summary, the developed unit was shown to allow an efficient control of the output hydrogen pressure that can be used in various applications including safe and simple in operation supply of laboratory facilities with high-pressure hydrogen gas.

The feasibility to generate up to 200 bar $\mathrm{H}_{2}$ pressure by a $\mathrm{MH}$ compressor using $\mathrm{AB}_{5} \mathrm{H}$ storage alloys and temperatures less than $200^{\circ} \mathrm{C}$ was shown as well.

\section{MODELLING A TWO-STEP MH COMPRESSOR: SIMULATION OF A DOMESTIC REFUELLER}

Unlike petrol and diesel, hydrogen can easily be generated on site and therefore the energy can be distributed by electrons via the electricity grid, or where there is a local renewable energy source, zero 
carbon hydrogen can be generated. The developments both in passenger and commercial hydrogen vehicles are making it more attractive for end users to generate their own hydrogen to either service a single vehicle (much like the attraction of plug-in hybrids) or a small fleet of vehicles (this could either be a community facility for domestic use or for a commercial fleet). The domestic refueller concept is based on the premise that the average car owner drives less than 40 miles per day which equates to ca. $600 \mathrm{~g}$ of H2. Based on a multistage $\mathrm{MH}$ compressor system and $1.5 \mathrm{~kW}$ electrolyser the domestic refueller would be capable of providing an overnight top up of an $\mathrm{H}_{2}$ FCEV in preparation for the following days commute at a target pressure of 350 bar.

\subsection{Numerical Simulation}

The successful operation of a multistage $\mathrm{MH}$ compressor system introduces strict requirements into the tuneability of the Pressure-Composition-Isotherm ( $\mathrm{PCl}$ ) characteristics. The plateau pressure for the hydrogenation process of the first stage material should be sufficiently low in order for the material to be able to absorb the hydrogen from the low pressure supplied by the electrolyzer. The coupling of the first stage (dehydrogenation) and the second stage (hydrogenation) requires the plateau pressure $\left(p_{\text {eq }}\right)$ of the stage $1 \mathrm{MH}$ to be higher than that for stage $2 \mathrm{MH}$. The higher the pressure differential between stage $1 \& 2$ plateau pressures then greater the force that delivers the transfer of hydrogen from the first to second stage tanks and drives the second stage hydrogenation. In order to achieve a sufficiently high compression ratio to meet the target 350 bar delivery pressure, the plateau pressure of the dehydrogenation process for the second stage material should be as high as possible. Fig. 12 illustrates the two-stage compression cycle on a van't Hoff plot, where it is assumed that stage 1 and stage 2 hydride beds share the same temperature range of low temperature, $T_{L}$, up to a high temperature $T_{H}$. The compression cycle process is summarized as follows: Step A: A low-pressure hydrogen supply (e.g. an electrolyzer) is attached to the first stage, at pressure $P_{s}$. The temperature of stage 1 is maintained at $T_{L}$, during hydrogenation. Step B-C: A sensible heating process for the stage 1 metal hydride bed occurs heating the bed to $T_{H}$ increasing the pressure of the stage 1 vessel. Step D-E: A coupling process between stage 1 (dehydrogenation at $T_{H}$ ) and stage 2 (hydrogenation at $T_{L}$ ) occurs. Step F-G: Stage 2 hydride bed undergoes sensible heating in order to achieve the delivery pressure of $P_{d}$. Step H: During dehydrogenation of stage 2 high pressure hydrogen is released from the compressor at $\mathrm{P}_{d}$.

Fig. 12 PLEASE, INSERT HERE 
The additional complexity in design of this application that two coupled $\mathrm{MH}$ reactors introduce warrants the use of a numerical model [7] in order to predict the overall compressor performance. Once validated, a numerical model will allow the timely optimization of specific system parameters and the incorporation of enhanced heat management techniques leading to the improvement of overall compressor performance.

\subsection{Assumptions}

The following assumptions are made simplifying the $\mathrm{MH}$ compression operation for purposes of this analysis:

a) Initially the $\mathrm{MH}$ bed temperature and pressure profiles are uniform.

b) Thermal conductivity and specific heat of the $\mathrm{MH}^{\prime}$ s are assumed constant during the compression cycle.

c) The $\mathrm{MH}$ and hydrogen gas are in local thermal equilibrium which implies that there is no heat transfer between solid and gas phases.

d) The hydrogen gas can be treated as an ideal gas from a thermodynamic point of view.

\subsection{Heat Equation}

Assumption c), thermal equilibrium between the hydride powder and hydrogen gas, allows the numerical model to be implemented by solving a single heat equation in place of separate equations for the solid and gas phases:

$$
\begin{aligned}
& (\rho \cdot C p)_{e} \cdot \frac{\partial T}{\partial t}+\left(\rho_{g} \cdot C p_{g}\right) \cdot \bar{v}_{g} \cdot \nabla T \\
& =\nabla \cdot\left(k_{e} \cdot \nabla T\right)+m \cdot\left(\left(\frac{\Delta \mathrm{H}}{M_{H_{2}}}\right)-T \cdot\left(C p_{g}-C p_{s}\right)\right)
\end{aligned}
$$

Where, the effective heat capacity is given by;

$$
(\rho \cdot C p)_{\mathrm{e}}=\varepsilon \cdot \rho_{g} \cdot C_{p g}+(1-\varepsilon) \cdot \rho_{s} \cdot C_{p s}
$$

and the effective thermal conductivity is given by;

$$
k_{e}=\varepsilon \cdot k_{g}+(1-\varepsilon) \cdot k_{s}
$$

The terms $\rho_{g}, C_{p g}, C_{p s}$ and $m$ refer to the density of the gas phase, the heat capacity of the gas phase, the heat capacity of the solid phase and the kinetic term for the reaction respectively.

\subsection{Hydrogen Mass Balance}

The equation that describes the diffusion of hydrogen mass inside the metal matrix is:

$$
\varepsilon \frac{\partial\left(\rho_{g}\right)}{\partial t}+\operatorname{div}\left(\rho_{g} \overrightarrow{v_{g}}\right)= \pm m
$$


where, $(-)$ is for the hydrogenation process and $(+)$ is for the dehydrogenation process, $v_{g}$ is the velocity of gas during diffusion within the metal lattice (see chapter 2.5 below) and $m$ is the mass of hydrogen diffused per unit time and unit volume in the metal lattice.

\subsection{Momentum Equation}

The velocity of a gas passing through a porous medium can be expressed by Darcy's law. By neglecting the gravitational effect, the equation which gives the velocity of gas inside the metal matrix is given by:

$$
\vec{v}_{g}=-\frac{K}{\mu_{g}} \cdot \operatorname{grad}\left(\vec{P}_{g}\right)
$$

where $\mathrm{K}$ is the permeability of the solid and $\mu_{\mathrm{g}}$ is the dynamic viscosity of gas.

\subsection{Kinetic Expression}

The amount of hydrogen taken up by the hydride bed during hydrogenation is given by;

$$
m_{a}=C_{a} \cdot \exp \left[-\frac{E_{a}}{R_{g} \cdot T}\right] \cdot \ln \left[\frac{p_{g}}{P_{e q}}\right] \cdot\left(\rho_{s s}-\rho_{s}\right)
$$

The amount of hydrogen released from the hydride bed during dehydrogenation is given by;

$$
m_{d}=C_{d} \cdot \exp \left[-\frac{E_{d}}{R_{g} \cdot T}\right] \cdot\left(\frac{P_{e q}-p_{g}}{P_{e q}}\right) \cdot \rho_{s}
$$

Where $\rho_{s}$ and $\rho_{s s}$ are the density of the hydride at any time and at saturation state respectively. $C_{a b s}$ and $C_{d e s}$ refer to the pre-exponential constants and the $E_{a}$ and $E_{d}$ are the activation energy for hydrogenation and dehydrogenation process respectively.

\subsection{Equilibrium Pressure}

In order to incorporate the effect of hysteresis and the plateau slope (which is present in both stages of the compression cycle) into the calculation of the plateau pressure $P_{e q}$, the following equation was used $[24,25]$

$$
\ln P_{e q}=\left[\frac{\Delta \mathrm{H}}{R T}-\frac{\Delta S}{R}+\left(\varphi_{s} \pm \varphi_{0}\right) \cdot \tan \left[\pi \cdot\left(\frac{x}{x_{\text {sat }}}-\frac{1}{2}\right) \pm \frac{S}{2}\right] \cdot 10^{5}\right.
$$

where $\varphi_{s}$ and $\varphi_{o}$ describe the plateau flatness factors and $S$ is the factor which can describes the hysteresis $\left(\mathrm{InP} \mathrm{P}_{\mathrm{abs}} / \mathrm{P}_{\text {des }}\right)$. Furthermore ' + ' refers for the hydrogenation process, while '-' refers for the dehydrogenation process and $x$ and $x_{\text {sat }}$ are the hydrogen concentration at any given time and fully saturated. 


\subsection{Mass and Energy Balance during Multistage reactor coupling}

During the coupling between the two reactors (stage 1-dehydrogenation process and stage 2-hydrogenation process), the total number of the hydrogen moles in the space of the connector between stage 1 and stage 2 at any time is given by;

$$
n_{t+d t}=n_{t}+n_{d e s}-n_{a b s}
$$

where, $n_{t}$ and $n_{t}+d_{t}$ are, respectively, the number of hydrogen moles in the total space at any time $t$ and $t+d t$. The number of the moles of hydrogen released from the stage 1 during the dehydrogenation process are $n_{\text {des }}$ and the number of hydrogen moles stored in stage 2 in a small time $d t$ are $n_{\text {abs. }}$. At any time the gas pressure in the connecting pipe between the two rectors, which is the driving force for both the hydrogenation and dehydrogenation process is calculated by;

$$
P_{t+d t}=\frac{n_{t+d t} \cdot R \cdot T_{t+d t}}{V_{d e s}+V_{a b s}}
$$

where, $T_{t+d t}$ is the temperature of gas in the connecting pipe, $V_{\text {des }}$ and $V_{a b s}$ are the free volume of the reactors during the dehydrogenation process $\left(V_{\text {des }}\right)$ and the hydrogenation process $\left(V_{a b s}\right)$. The pressure in the connecting pipe acts as the driving force for both the dehydrogenation and the hydrogenation process, so for the coupling case the kinetics for the dehydrogenation and the hydrogenation are calculated by;

$$
\begin{aligned}
& m_{d e s}=C_{d e s} \exp \left[-\frac{E_{d e s}}{R T}\right] \cdot \frac{P_{e q}-P_{t+d t}}{P_{e q}} \cdot \rho_{s} \\
& m_{a b s}=C_{a b s} \exp \left[-\frac{E_{a b s}}{R T}\right] \cdot \ln \left(\frac{P_{t+d t}}{P_{e q}}\right) \cdot \Delta \rho_{s}
\end{aligned}
$$

Validation of the numerical model was achieved through comparing the model with the experimental work given in [7].

\subsection{Simulation results and analysis} A numerical simulation was conducted using COMSOL Multiphysics Version 4.3b, a finite element based numerical solver. The initial temperature of the first stage hydrogenation process and dehydrogenation processes were $20^{\circ} \mathrm{C}$ and $130^{\circ} \mathrm{C}$ respectively and the properties of the first stage material were those of an $A B_{5}\left(L_{0.85} \mathrm{Ce}_{0.15} \mathrm{Ni}_{5}\right)$ alloy while the properties of the second stage material were based on an $\mathrm{AB}_{2}(\mathrm{Zr}-\mathrm{V}-\mathrm{Mn})$ 
alloy. The initial pressure for the stage was 15 bar, representing the pressure that a commercial electrolyzer can provide. Fig. 13 shows the average bed temperature for the two-stage compression system. A complete two-stage compression cycle consists of one non-coupled hydrogenation process (stage 1), one coupled dehydrogenation (stage 1)-hydrogenation (stage 2) process, a dehydrogenation process (stage 2) and two sensible heating processes (stage 1 and stage 2). For clarity, the two sensible heating processes have not been shown but are represented in Fig. 13 and 14 by the vertical dashed line at the end of the first stage hydrogenation process, the coupling and the beginning of the dehydrogenation process. After the hydrogenation process of stage 1 , sensible heating takes place raising the temperature inside the reactor from 20 to 130 C. Fig. 14 shows the bed average pressure evolution of the compression system. Initially, during the hydrogenation process of the first stage, the hydrogen pressure within the reactor drops during to the formation of the metal hydride. At the beginning of the coupling there is a maximum pressure difference between the two reactors of 20 bar. During the initial coupling this pressure difference equalizes resulting in the pressure of stage 1 decreasing sharply from 40 bar and the pressure of stage 2 increasing rapidly from 20 bar. After the pressure equalizes across both reactors the continuation of the coupling process results in a gradual increase in pressure until it reaches the equilibrium of the driving potential between the two reactors. The insert picture in Fig. 14 is of the coupled stage 1 and 2 reactors and illustrates the relatively fast kinetics of the two systems.. At the end of the compression the simulated system achieves a pressure of 325 bar resulting in a pressure ratio of 22:1.

Fig. 13. PLEASE, INSERT HERE

Fig. 14. PLEASE, INSERT HERE 


\section{RECENT DEVELOPMENTS OF INDUSTRIAL-SCALE METAL HYDRIDE HYDROGEN COMPRESSORS}

3.1. HYMEHC-5 and HYMEHC-10 - the thermal hydrogen compressors by HYSTORSYS Two full-scale proof-of-concept compressor systems have been constructed: one HYMEHC-10 $\left(10 \mathrm{Nm}^{3} / \mathrm{h}\right.$ thermal hydrogen compressor) and one HYMEHC-5 (5 Nm $3 / \mathrm{h})$. The compressor systems are CE-marked and constructed for operation in Ex Zone 2 (according to IEC 60079-10-1, standard covering hazardous area classification for gases).

The HYMEHC-10 proof-of-concept thermal hydrogen compressor was developed and delivered to the HyNor Lillestrøm refueling station located in Akershus Energy Park about $25 \mathrm{~km}$ northeast of Oslo as a part of the user-driven innovation project HyNor Lillestrøm founded by The Research Council of Norway, Akershus County Council, Transnova, Innovation Norway and Akershus Energy (www.hynor-lillestrom.no). In addition to being a refueling station for hydrogen vehicles, HyNor Lillestrøm is a research and demonstration center for new hydrogen technologies.

The HYMEHC-10 unit shown in Fig. 15 was installed at HyNor Lillestrøm as a continuously operated compressor system increasing the pressure from 10 bar up to 200 bar at a throughput rate of $10 \mathrm{Nm}^{3} / \mathrm{h}$.

Fig. 15 PLEASE, INSERT HERE

This metal hydride based hydrogen compressor consists of three high-pressure steel vessels for each of the two stages. Each of the six vessels contains about $34 \mathrm{~kg}$ of metal hydride material. An $A B_{5}$-alloy $\left(\mathrm{La}_{1-\mathrm{x}} \mathrm{Ce}_{\mathrm{x}} \mathrm{Ni}_{5}\right)$ is used for the first compression stage from 10 to 50 bar, while an $\mathrm{AB}_{2}$-alloy ( $\mathrm{Ti}, \mathrm{Zr}$-based) is used for the second stage from 50 to $200 \mathrm{bar}$. The $\mathrm{MH}$-system operates with thermal cycles between 20 and $150^{\circ} \mathrm{C}$, and requires only a small amount of electricity to power valves and other small pieces of auxiliary equipment.

An electrical external oil heater with a maximum capacity of $27 \mathrm{~kW}$ is installed to emulate the "industrial process heat", and the heat transfer to the MH-compressor is facilitated by a heating oil loop using the commercially available oil THERMINOL ${ }^{\circledR L T}$.

Thermal management of the compressor is based on two pressurized closed oil loops. Each of the six metal hydride vessels is equipped with two 3-way valves selecting the hot or the cold oil according to the thermal sequence diagram making only the compartment of the compressor vessels common for the two oil loops. Circulation of the oil is provided by means of two high-temperature circulation pumps. The flow of hydrogen is controlled by means of pneumatic shut-off valves. Each of the six pressure vessels is equipped with a pressure sensor and a temperature sensor continuously probing the "state" of each vessel. In addition, safety relief valves (burst pressure 250 bar) are implemented for each unit as well as at the compressor input/output. 
The commissioning of the HYMEHC-10 at the HyNor Lillestrøm refueling station started in May 2013. This system has been successfully tested and put into operation. Up to now HYMEHC-10 has been operated for about 3500 hours, including a near month of operation in non-stop regime. The only maintenance during operating period was a replacement of a shut-off valve on hydrogen line (due to internal leakage), after about 2000 operation hours. Fig. 16 shows hydrogen pressures at different stages of hydrogen compression during operation of HYMEHC-10 (oil temperatures are $\sim 24^{\circ} \mathrm{C}$ for cold loop and $\sim 120^{\circ} \mathrm{C}$ for hot loop).

Fig. 16 PLEASE, INSERT HERE

The HYMEHC-5 proof-of-concept system was developed as part of the Eurostars project HYPROCOM that was carried out in collaboration with the Dutch reformer company HyGear (www.hygear.nl) and the industrial gas company Air Products (www.airproducts.com). The two-stage compressor has been constructed for continuous operation increasing the pressure from approximately 5 bar up to 230 bar (burst pressure for safety valves: $250 \mathrm{bar}$ ) at a throughput rate of $5 \mathrm{Nm}^{3} / \mathrm{h}$ exploiting thermal energy of maximum $150^{\circ} \mathrm{C}$.

In general, the configuration of the "HYPROCOM" HYMEHC-5 compressor is the same as and the instrumentation is similar as for the HYMEHC-10 described above. The main deviations compared to the HYMEHC-10 system are: (a) the lower hydrogen throughput rate, (b) the lower input pressure level / higher output pressure level, and (c) the thermal integration with respect to the steam methane reformer (SMR) from HyGear.

The HYMEHC- 5 was put into operation at the test-site of NEL Hydrogen (Notodden, Norway) for internal R\&D making HYSTORSYS ready for deliveries of thermal hydrogen compressor systems. The results of a continuous $25 \mathrm{~h}$ test operation of HYMEHC-5 at an upper temperature of $140^{\circ} \mathrm{C}$ are shown in Fig. 17.

\section{Fig. 17 PLEASE, INSERT HERE}

\section{2. $\mathrm{MH}$ hydrogen compressor by SAIAMC / UWC (3-200 bar $\left.5 \mathrm{Nm}^{3} / \mathrm{h} \mathrm{H}_{2}\right)$} A compressor was built by SAIAMC / UWC for the industrial customer, Eskom Holdings Ltd. (South Africa) for capturing low-pressure $\mathrm{H}_{2}\left(P_{L} \sim 3\right.$ bar) delivered from PSA purification system and delivering the gas into standard gas cylinders at the pressure $P_{H}=200$ bar. The available services necessary for the $\mathrm{H}_{2}$ compression include low-grade steam $\left(T_{H}=130-150^{\circ} \mathrm{C}\right)$ and circulating cooling water $\left(T_{L}=20-25^{\circ} \mathrm{C}\right)$.

Preliminary analysis showed that the specified pressure - temperature requirements can be met using three-stage compressor layout. Fig. 18 presents PCT characteristics of $\mathrm{MH}$ materials selected for the stage 1 (A; $\left.\mathrm{LaNi}_{4.9} \mathrm{Sn}_{0.1}\right), 2\left(\mathrm{~B} ; \mathrm{La}_{0.8} \mathrm{Ce}_{0.2} \mathrm{Ni}_{5}\right)$ and 3 (C; $\mathrm{C} 14-\mathrm{Ti}_{0.65} \mathrm{Zr}_{0.35}(\mathrm{Mn}, \mathrm{Cr}, \mathrm{Fe}, \mathrm{Ni})_{2}$ with the additive of $10 \mathrm{wt} . \%$ of $\mathrm{La}_{0.8} \mathrm{Ce}_{0.2} \mathrm{Ni}_{5}$ to facilitate the activation).

Fig. 18 PLEASE, INSERT HERE 
As it can be seen from Fig. 18, the cycle productivity of the three-stage $\mathrm{H}_{2}$ compression is mainly determined by hydrogen absorption / desorption in the $\mathrm{AB}_{2}$-type material on stage 3 (C). In turn, at the given $T_{L}=25^{\circ} \mathrm{C}$, hydrogen concentration achieved in this material (circled area in Fig. $18 \mathrm{C}$ ) is strongly dependent on the intermediate pressure, $P_{\mathrm{M} 2}$ determined by PCT performance of the second stage material at $T=T_{H}$ (Fig. 18B). The reduction of $P_{\mathrm{M} 2}$ from $50\left(\mathrm{La}_{0.8} \mathrm{Ce}_{0.2} \mathrm{Ni}_{5}\right)$ to $40 \mathrm{~atm}\left(\mathrm{La}_{0.85} \mathrm{Ce}_{0.15} \mathrm{Ni}_{5}\right)$ results in the drop of the cycle productivity in 1.7 times, from 77 to $45 \mathrm{NL} / \mathrm{kg}$.

General views of the compressor are shown in Fig. 19. Apart from MH materials used for stages 1-3 (see above), the compressor has a number of original layout features, according to the engineering solution recently patented by UWC [26]. The main layout features aimed at the maximizing of the throughout capacity include:

(i) special gas piping allowing to apply different time setpoints for the heating and cooling which are optimal for the selected metal hydride materials and containers;

(ii) variation in the size of $\mathrm{MH}$ containers for stages 1, 2 and 3 allowing to increase pressure driving forces $\left(P_{\mathrm{M} 1}, P_{\mathrm{M} 2}\right)$ in between the stages;

(iii) hydrogen purification option, by partial release of contaminated $\mathrm{H}_{2}$ from the stage $1 \mathrm{MH}$ containers at the beginning of the heating / $\mathrm{H}_{2}$ desorption;

(iv) optimisation of the layout of the $\mathrm{MH}$ container allowing to improve its heat transfer performances;

(v) optimisation of heating / cooling piping diagram towards the increase of the heating / cooling efficiency and reduction of consumption of steam and water. In particular, usage of steam traps allowed us to significantly improve the heating efficiency above $100{ }^{\circ} \mathrm{C}$ and to achieve the steam consumption below $30 \mathrm{~kg} / \mathrm{h}$ during the operation.

Hydrogen compression is provided by 12 metal hydride containers assembled in two compression modules. Each module comprises six $\mathrm{MH}$ containers (by two for each stage) which can be heated or cooled simultaneously, to provide higher pressure $\mathrm{H}_{2}$ desorption and lower pressure $\mathrm{H}_{2}$ absorption, respectively. The heating and cooling times can be set separately within the limits 15 to 45 minutes. The amount of the $\mathrm{MH}$ material in one container varies from $17 \mathrm{~kg}$ (stage 1) down to $12.5 \mathrm{~kg}$ (stage 3) according to the feature (ii) listed above. The operation of the compressor is provided via a Program Logic Controller (PLC), by the periodic opening and closing solenoid valves in the gas (stage 1 only) and steam / water piping circuits. Switching of high-pressure gas flows (stages $2-3$ ) is provided automatically by a corresponding check valve arrangement. 
Fig. 19 PLEASE, INSERT HERE

The compressor is able to compress hydrogen from 3 to 200 bar with average throughout capacity about 5 $\mathrm{Nm}^{3} / \mathrm{h}$ using direct steam heating $\left(T_{H}=130^{\circ} \mathrm{C}\right)$ and water cooling $\left(T_{L}=25^{\circ} \mathrm{C}\right)$ to drive the $\mathrm{H}_{2}$ compression. It was shown that the operating pressure range can be as wide as 1-240 bar at the same heating / cooling conditions, but in this case the throughout capacity significantly drops

\section{SUMMARY, CONCLUDING REMARKS AND FUTURE PROSPECTS}

The main challenges in the development of the $\mathrm{MH}$ compressors include achievement of the necessary compression ratios within the available operation temperature range, as well as increase of the throughout capacity / productivity, cycle lifetime and improvement of the energy efficiency. These problems, being particularly critical for the industrial-scale multistage $\mathrm{MH}$ compressors, are addressed by (i) proper selection and development of the $\mathrm{MH}$ alloys; (ii) improvement of the dynamic performances of the $\mathrm{MH}$ containers; and (iii) optimisation of the overall system layout.

As mentioned, several research teams continue further investigations of the $A B_{2}$ alloys and $A B_{5}$ alloys. These two groups of materials offer considerable potential possibilities for the optimization in both the alloys composition and in the technologies of their processing allowing to reach the desired performance levels.

The improvement of the dynamic performances of $\mathrm{MH}$ containers for $\mathrm{H}_{2}$ compressors, as well as the whole system optimisation, implies a precise modelling of the heat-and-mass transfer in the $\mathrm{MH}$ beds coupled in the multi-stage layouts. The increase of the modelling accuracy is very important and can be achieved, first of all, by the appropriate description of the PCT relationships in the metal-hydrogen systems. Based on the results of the modelling, advanced engineering solutions of both system components and general layout features may be drawn resulting in the solution of the problems specified above.

In general, the $\mathrm{MH}$-compressors can serve a number of markets such as traditional industry, renewable energy, emergency power, hydrogen fuel infrastructure, etc. While some of these markets are still small but are emerging, hydrogen can be readily used in a number of industrial processes already today. Importantly, many industrial chemical processes generate large amounts of the waste heat, that can be fed back to a MHcompressor compressing hydrogen for free. Thus, we observe a good match between the traditional industry and thermally driven metal hydride hydrogen compressors.

An overview conceptual drawing of an on-site hydrogen production / backup solution suggested by HYSTORSYS AS for industrial applications is shown in Fig. 20 [34]. Here, the industrial process is continuously fed hydrogen from the on-site hydrogen generator (water electrolyser or reformer unit) while occasionally a small part of the hydrogen feed is compressed and stored for later use exploiting only thermal energy - e.g., waste heat from the industrial process. The purpose of the hydrogen backup system (comprising the compressor and the storage) is to provide hydrogen for the industrial process whenever the direct hydrogen 
supply line is down (e.g., for hydrogen generator maintenance, utility power interrupt or other sort of failures). The size of such a hydrogen backup storage might very much vary from application to application. However, since the main supply line only will be down occasionally and the interference with the continuous hydrogen feed should be at a minimum, usually a small to moderate compressor capacity would need to be installed in order to top off the backup storage.

Fig. 20 PLEASE, INSERT HERE

Fig. 21 presents an example of this approach recently implemented by SAIAMC / UWC for Impala Platinum Ltd. in South Africa [35]. The MH compressor is integrated in hydrogen refueling station (dispensing $\mathrm{H}_{2}$ pressure up to 185 bar) for the refueling of fuel cell forklifts. The dispensing is carried out from a buffer, standard cylinder pack ( $900 \mathrm{~L}$ in the inner volume, $\mathrm{H}_{2}$ pressure $200 \mathrm{bar}$ ) while the high pressure in the buffer is maintained by $\mathrm{MH}$ compressor which is fed from $\mathrm{H}_{2}$ pipeline consuming steam and cooling water available at the customer's site.

\section{Fig. 21. PLEASE, INSERT HERE}

It appears to be very promising to use metal hydride compressors for the industrial customers having in their possession low pressure hydrogen supplied by a pipeline. As the cost of the pipeline hydrogen is much lower than the cost of compressed $\mathrm{H}_{2}$ supplied in gas cylinders, use of the $\mathrm{MH}$ compression is becoming a significant economic driver for the industrial-scale implementation of the $\mathrm{MH}$ compression technology. Even prototype $\mathrm{MH}$ compressors require only reasonable investments while keeping the low operation costs [1] in cases where instead of utilising expensive electric power, the services already existing in the customer's infrastructure (low-grade steam and circulating cooling water) can be utilised to offer economically efficient $\mathrm{H}_{2}$ compression.

\section{ACKNOWLEDGEMENTS}

This work is a part of the activities within IEA Task 32 Hydrogen Based Energy Storage. We are grateful for the task coordinator Dr. Michael Hirscher and all the experts from the Task 32 for the fruitful collaboration.

Volodymyr A. Yartys acknowledges the support from the Research Council of Norway (project 191106 "Thermally Driven systems for Storage, Compression and Supply of Hydrogen Gas") and Nordic Energy Research (project NORSTORE).

Development and characterisation of $\mathrm{MH}$ materials for hydrogen compression was done via Program of Research Cooperation between Norway and South Africa funded by Research Council of Norway and NRF in South Africa ( Project \#180344 was coordinated by V.A. Yartys and M.V. Lototskyy).

Mykhaylo Lototskyy and Vladimir Linkov acknowledge support of Eskom Holdings Ltd and Impala Platinum Ltd (both South Africa) for the funding of the developments of MH hydrogen compressors at South African Institute for Advanced Materials Chemistry. Furthermore ML and VL acknowledge the support from the 
Department of Science and Technology (DST) in South Africa via Hydrogen South Africa National Flagship Hydrogen and Fuel Cell Programme (HySA; project KP3-S02).

David Grant, Alastair Stuart would like to thank the Engineering and Physical Science Research Council for funding under EP/K021117/1 and Evangelos Gkanas, Kandavel Manickam and Gavin Walker (University of Nottingham) for their valuable support.

HYSTORSYS AS would like to acknowledge the support and dedicated contribution from the Eurostarsprogramme and the HYPROCOM-partners HyGear B.V. and Air Products and Chemicals, Inc., Hynor Lillestrøm AS for hosting the compressor test site and managing the HyNor-project, the founding bodies of the HyNor Lillestrøm-project being the Research Council of Norway, Akershus County Council, Transnova, Akershus Energy and Innovation Norway, and last but not least - Norsk Innovasjonskapital III AS (NIK III) for their committed financing of the company.

Robert C. Bowman, Jr. thanks the Fuel Cell Technology Office of the U.S. Department of Energy, Office of Energy Efficiency and Renewable Energy for their support of his work at the Oak Ridge National Laboratory. This manuscript has been authored by UT-Battelle, LLC, under Contract No. DE-AC05-00OR22725 with the U.S. Department of Energy. The United States Government retains and the publisher, by accepting the article for publication, acknowledges that the United States Government retains a nonexclusive, paid-up, irrevocable, world wide license to publish or reproduce the published form of this manuscript, or allow others to do so, for United States Government purposes.

VAY and ML appreciate help from Latchezar Bozoukov (LabTech Int. Co. Ltd.), Dyre Rostald (Raufoss Fuel Systems ASA), Prof. Jan Ketil Sollberg (Norwegian University of Science and Technology), as well as Jan Petter Maehlen, Nils Jorgen Svensen and Kristin Wickstrøm (Institute for Energy Technology) received at various stages of the work on the metal hydride compression at Institute for Energy Technology .

\section{REFERENCES}

1. Lototskyy MV, Yartys VA, Pollet BG, Bowman Jr RC. Metal hydride hydrogen compressors: A review. Int J Hydrogen Energy 2014; 39: 5818-51

2. E.D. Koultoukis, S.S. Makridis, E. Pavlidou, P. de Rango, A.K. Stubos. Investigation of $\mathrm{ZrFe}_{2}$-type materials for metal hydride hydrogen compressor systems by substituting $\mathrm{Fe}$ with $\mathrm{Cr}$ or $\mathrm{V}$. Int J Hydrogen Energy 39 (2014) 21380-21385

3. L.Pickering, D. Reed, A.I. Bevan, D. Book. Ti-V-Mn based metal hydrides for hydrogen compression applications. Journal of Alloys and Compounds 645 (2015) S400-S403

4. S.A. Obregón, M.R. Esquivel. A quantitative analysis of the hydrogen sorption isotherms of $\mathrm{MmNi}_{4.25} \mathrm{Al}_{0.75}$. Procedia Materials Science 8 (2015) $752-759$

5. S.P. Malyshenko, S.V. Mitrokhin, I.A. Romanov. Effects of scaling in metal hydride materials for hydrogen storage and compression. Journal of Alloys and Compounds 645 (2015) S84-S88

6. B. Satya Sekhar, P. Muthukumar. Development of double-stage metal hydride-based hydrogen compressor for heat transformer application. J. Energy Eng. (2014) 10.1061/(ASCE)EY.19437897.0000246, 04014049 
7. E.I. Gkanas, D.M. Grant, A.D. Stuart, C.N. Eastwick, D. Book, S. Nayebossadri, L. Pickering, G.S. Walker. Numerical study on a two-stage metal hydride hydrogen compression system. Journal of Alloys and Compounds 645 (2015) S18-S22

8. M.M.H.Bhuiya, C.Y. Lee, T.Hwang, S.Munira, R.Hopkins, H.Yoon, S.H.Park, K.J. Kim. Experimentally tuned dual stage hydrogen compressor for improved compression ratio. Int J Hydrogen Energy 39 (2014) 12924-12933

9. Y.K. Baichtok, A.K. Avetisov, Y.M. Baranov, R.G. Telyashev, V.Z. Mordkovich, S.V. Suvorkin, A.N. Obryvalina, N.V.Dudakova, G.V. Kosarev, N.A.Kostikov. Housing-tubular module of hydride thermal sorption hydrogen separator-compressor. Patent application US 2014/0311348 A1, 23.10.2014

10. M.M.H.Bhuiya, A.Kumar, K.J. Kim. Metal hydrides in engineering systems, processes, and devices: A review of non-storage applications. Int J Hydrogen Energy 40 (2015) 2231-2247

11. B.R.S. Hansen, K.T. Møller, M.Paskevicius, A.C. Dippel, P.Walter, C.J.Webb, C.Pistidda, N.Bergemann, M. Dornheim, T.Klassen, J.E. Jørgensen, T.R.Jensen. In situ X-ray diffraction environments for high-pressure reactions. J Appl Cryst 48 (2015) 1234-1241

12. M.M.H.Bhuiya. Design and Analysis of Hydrogen Powered Actuator Integrating Metal Hydride Storage System. PhD Thesis, University of Nevada, Las Vegas, 2014. Downloaded from Digital Scholarship@UNLV, http://digitalscholarship.unlv.edu/thesesdissertations

13. Lototsky MV, Yartys VA, Marinin VS, Lototsky NM. Modelling of phase equilibria in metal-hydrogen systems. J Alloys Compds 2003; 356-357: 27-31

14. M.Lototskyy, Ye.Klochko, V.Linkov, P.Lawrie, B.G.Pollet. Thermally Driven Metal Hydride Hydrogen Compressor for Medium-Scale Applications. Energy Procedia 29 (2012) 347-356

15. Kierstead HA. A theory of multiplateau hydrogen absorption isotherms. J Less-Common Met 1980; 71 : 303-9.

16. R.H.Wiswall, J.J.Reilly. Method of storing hydrogen.- US patent 3516263 (1970)

17. A.N.Golubkov, S.K.Grishechkin, A.A.Yukhimchuk System for investigation of hydrogen isotopes - solid body interaction at $500 \mathrm{MPa}$.- Int. J. Hydrogen Energy 26 (2001) 465-468

18. Yu.F.Shmal'ko, V.V.Solovey, M.V.Lototsky, E.V.Klochko, I.Yu.Zavaliy, O.B.Ryabov, V.A.Yartys. Metalhydride systems for processing hydrogen isotopes for power plants. - Materials Science, 37 (5) 2001 689-706

19. M.V.Lototsky, A.F.Savenko, D.V.Schur, V.K.Pishuk, V.A.Yartys, A.P.Mukhachev. Metal hydride unit for hydrogen storage / compression.- Hydrogen Materials Science and Chemistry of Carbon Nanomaterials (ICHMS'2005), IX Int. Conf., Sevastopol - Crimea - Ukraine, September 05-11, 2005, p.822-825

20. G.Sandrock. A panoramic overview of hydrogen storage alloys from a gas reaction point of view.- J. Alloys and Compounds 293-295 (1999) 877-888

21. B.A.Kolachev, R.E.Shanin, A.A.Il'in. Hydrogen Storage Alloys / Reference Book, Moscow, "Metallurgy" Publ., 1995 (in Russian)

22. K. Nasako, Y. Ito, N. Hiro, M. Osumi. Stress on a reaction vessel by the swelling of a hydrogen absorbing alloy.- J. Alloys Comp 264 (1998) 271-276

23. V.Yartys, M.Lototsky, Y.Tranøy, R.Glöckner. Hydrogen Storage and Applications: An Overview.- Report IFE/KR/F-2003/

24. Y. Liu, H. Wang, A. K. Prasad, S. G. Advani, "Role of heat pipes in improving the hydrogen charging rate in a metal hydride storage tank", Int. J. Hydrogen Energy 39 (2014) 10552-10563

25. K.J. Kim, G.M. Lloyd, K.T. Feldman Jr , A., Razani, "Thermal analysis of the $\mathrm{Ca}_{0.4} \mathrm{Mmm}_{0.6} \mathrm{Ni}_{5}$ metal-hydride reactor", Appl. Therm. Eng. 18 (1998) 1325-1336. 
26. M.V. Lototskyy, D.Swanepoel, M.W.Davids, Y.Klochko, B.J. Bladergroen, V.M. Linkov. Multistage metal hydride hydrogen compressor. Patent application ZA 2015/01837, 18.03.2015

27. E. D. Koultoukis, S. S. Makridis, D. Fruchart, A. K. Stubos, "Two-stage Hydrogen Compression Using Zrbased Metal Hydrides" Solid State Phenomena 194 (2013) 249-253.

28. E. D. Koultoukis, E. I Gkanas, S. S. Makridis, C. N. Christodoulou, D. Fruchart, A. K. Stubos, "Hightemperature activated $\mathrm{AB}_{2}$ nanopowders for metal hydride hydrogen compression", Int. J. Energy Res. 35 (2014) 477-486.

29. B.A. Talaganis, M.R. Esquivel, G. Meyer, "A two-stage hydrogen compressor based on ( $\mathrm{La}, \mathrm{Ce}, \mathrm{Nd}, \mathrm{Pr}) \mathrm{Ni}_{5}$ intermetallics obtained by low energy mechanical alloying - Low temperature annealing treatment", Int. J. Hydrogen Energy. 34 (2009) 2062 -2068.

30. B.A. Talaganis, M.R. Esquivel, G. Meyer, "Improvement of as-milled properties of mechanically alloyed $\mathrm{LaNi}_{5}$ and application to hydrogen thermal compression", Int. J. Hydrogen Energy 36 (2011) 1196111968.

31. S.A. Obregon, J.J. Andrade-Gamboa, M.R. Esquivel, "Synthesis of Al-containing $\mathrm{MmNi}_{5}$ by mechanical alloying: Milling stages, structure parameters and thermal annealing", Int. J. Hydrogen Energy 37 (2012) 14972-14977.

32. S.A. Obregon, M.R. Esquivel, "Scheme of thermal compression of hydrogen (TCH) using $\mathrm{MmNi}_{4.25} \mathrm{Al}_{0.75}$ recovered with ethyl alcohol and handled under non protective atmospheres" Int. J. Hydrogen Energy. 39 (2014) 8577-8581.

33. M. Odysseos, P. De Rango, C.N. Christodoulou, E.K. Hlil, T. Steriotis, G. Karagiorgis, G. Charalambopoulou, T. Papapanagiotou, A. Ampoumogli, V. Psycharis, E. Koultoukis, D. Fruchart, A. Stubos, "The effect of compositional changes on the structural and hydrogen storage properties of (La$\mathrm{Ce}) \mathrm{Ni}_{5}$ type intermetallics towards compounds suitable for metal hydride hydrogen compression", J. Alloys Compds. 580 (2013) S268-S270.

34. HYSTORSYS AS, HYMEHC-04 Expandable, data sheet, 2015

35. M.V.Lototskyy, I.Tolj, M.W.Davids, Y.Klochko, A.Parsons, D.Swanepoel, F.Smith, B.G.Pollet, C.Sita, V.Linkov. Metal Hydride Hydrogen Storage and Supply Systems for Electric Forklift with LT PEMFC Power Module, 10th Conference on Sustainable Development of Energy, Water and Environment Systems (SWEDES2015), September 27 - October 2, 2015, Dubrovnik, Croatia, Special Section "Hydrogen and Fuel Cells", presentation SDEWES2015-0441 


\title{
FIGURE CAPTIONS IN THE PAPER \\ METAL HYDRIDE HYDROGEN COMPRESSION: RECENT ADVANCES AND FUTURE PROSPECTS
}

by

\author{
Volodymyr A. Yartys, Mykhaylo Lototskyy, Vladimir Linkov, David Grant. Alastair Stuart, \\ Jon Eriksen, Roman Denys and Robert C. Bowman, Jr.
}

Figure 1. Temperature dependence of plateau pressure, $P_{P}$, for the systems of gaseous $\mathrm{H}_{2}$ with $\mathrm{La}_{0.85} \mathrm{Ce}_{0.15} \mathrm{Ni}_{5}$ (1) and $\mathrm{C}_{14}-\mathrm{Ti}_{0.65} \mathrm{Zr}_{0.35}(\mathrm{Mn}, \mathrm{Cr}, \mathrm{Fe}, \mathrm{Ni})_{2}$ (2). Both dependencies are presented for $\mathrm{H}$ desorption at $\mathrm{H}$ concentration in the solid equal to $75 \mathrm{NL} / \mathrm{kg}$ that corresponds to $H / A B_{5}=2.90$ and $H / A B_{2}=1.15$. The rectangular area corresponds to pressures and temperatures during $\mathrm{H}_{2}$ absorption in stage 2 in the course of two-stage operation.

Figure 2. Isotherms of hydrogen absorption at $T_{L}=20^{\circ} \mathrm{C}(\mathrm{a})$ and desorption at $T_{H}=130^{\circ} \mathrm{C}(\mathrm{d})$ for the systems of gaseous $\mathrm{H}_{2}$ with $\mathrm{La}_{0.85} \mathrm{Ce}_{0.15} \mathrm{Ni}_{5}(1)$ and $\mathrm{C} 14-\mathrm{Ti}_{0.65} \mathrm{Zr}_{0.35}(\mathrm{Mn}, \mathrm{Cr}, \mathrm{Fe}, \mathrm{Ni})_{2}(2)$. The circled area corresponds to the minimum amount of the transferred hydrogen $\left(\Delta C_{H}\right)$ in the course of two-stage $\mathrm{H}_{2}$ compression process ABCDEF.

Figure 3. Calculated PCT diagram for $\mathrm{H}$ absorption (solid lines) and desorption (dashed lines) in the mixture 90wt.\% C14-(Ti,Zr)(Mn, $\mathrm{Cr}, \mathrm{Fe}, \mathrm{Ni})_{2}+10 \mathrm{wt} . \% \mathrm{La}_{0.8} \mathrm{Ce}_{0.2} \mathrm{Ni}_{5}$.

Figure 4. Estimated enthalpies of hydride formation for cerium-substituted intermetallic $\operatorname{LaNi}_{5}(\mathrm{a})$ and the corresponding values of equilibrium hydrogen pressure at different temperatures (b) calculated assuming the entropy of the hydride formation equal to- $110 \mathrm{~J} /\left(\right.$ mole $\left._{2} \cdot \mathrm{K}\right)$ -

Figure 5. Calculated PCT diagram of the $\mathrm{H}$ storage alloy (wire-frame surface) obtained by the fitting of the experimental pressure-composition isotherms (shaded inverse triangles) and the experimental PCT data taken in the course of testing the unit (circles).

Figure 6. Calculated temperature dependencies of $\mathrm{H}$ desorption equilibrium pressure for the system $\mathrm{H}_{2}-$ $\mathrm{La}_{0.85} \mathrm{Ce}_{0.15} \mathrm{Ni}_{5}$ at different hydrogen concentrations; the values in percentage of the maximum hydrogen capacity $(155 \mathrm{NL} / \mathrm{kg})$ are shown as curve labels.

Figure 7. Control diagram (a), general overview (b), and gas communications (c, d) of $350 \mathrm{~L} / 200$ bar MH hydrogen storage and compression unit. $1-\mathrm{MH}$ container $(1 \mathrm{a}-$ cartridge electric heater, $1 \mathrm{~b}$ -

thermocouple), 2 - shut-off valves, 3 - safety relief valve, 4 - pressure sensor, $5-\mathrm{H}_{2}$ discharge line, $6-\mathrm{H}_{2}$ charge line, 7 - venting line, 8 - pressure controller, 9 - auxiliary temperature controller / indicator, 10 pressure indicator, 11 - power amplifier, 12 - fans.

Figure 8. Assembly drawing of the $\mathrm{MH}$ container. 1 - bottom SS flange, $1 \mathrm{a}-$ space for electric heater; 2 shell (SS tube); 3 - top flange, $3 a-\mathrm{H}_{2}$ input / output, $3 \mathrm{~b}-\mathrm{MH}$ loading; 4 - heat exchanger (SS tube / $\mathrm{Al}$ fins); 5 - filter (porous SS tube); 6 - thermocouple. 
Figure 9. Cyclogram of the operation of the $\mathrm{MH} \mathrm{H}$ storage and compression unit. The starting residual amount of stored hydrogen is equal to $182 \mathrm{NL}\left(83 \mathrm{NL} / \mathrm{kg}, \mathrm{H} / \mathrm{AB}_{5}=3.15\right)$.

Figure 10. Dependence of the unit's discharge flow rate on the residual hydrogen concentration in $\mathrm{MH}$. Points correspond to the measurements done in the course of different discharges of the unit to the total receiver volume $\sim 3$ litres, at pressure setpoint equal to 50 bar. Dashed line is plotted just to guide the eye.

Figure 11. Cost structure of the MH H storage and compression unit. The estimated labor costs correspond to 0.5 man-month total workload.

Figure 12. A van't Hoff plot illustrating the operation of a two-stage Metal Hydride Hydrogen Compression system from the low temperature $T_{L}$ to the high temperature $T_{H}$. A sensible heating process is performed after each hydrogenation process to increase Peq inside each compression stage. For clarity, the black lines represent the van't Hoff plot for the hydrogenation process for stage 1 (lower black line) and for stage 2 (upper black line).The coupling process between stage 1 and stage 2 is represented by the dashed line.

Figure 13. Bed average temperature evolution for a complete hydrogen compression cycle.

Figure 14. Bed average pressure evolution for a complete hydrogen compression cycle.

Figure 15. The HYMEHC-10 proof-of-concept compressor at HyNor Lillestrøm.

Figure 16. Hydrogen pressures in HYMEHC-10 compressor: $\mathrm{P}_{\text {in }}$-inlet pressure, $\mathrm{P}_{\mathrm{m}}$ - intermediate pressure after $1^{\text {st }}$ stage and $\mathrm{P}_{\text {out }}$ - outlet pressure after $2^{\text {nd }}$ stage.

Figure 17. Operating characteristics of HYMEHC-5 compressor: a) temperatures of heat transfer fluid (Duratherm 450) in cold $T_{\text {Low }}$ and hot $T_{\text {High }}$ oil loops; b) hydrogen pressures: inlet $P_{i n}$, intermediate $P_{m}$ and outlet $P_{\text {out }}$ and c) hydrogen throughput rate.

Figure 18. PCT characteristics of the $\mathrm{LaNi}_{4.9} \mathrm{Sn}_{0.1}(\mathrm{~A}), \mathrm{La}_{0.8} \mathrm{Ce}_{0.2} \mathrm{Ni}_{5}(\mathrm{~B})$ and $90 \mathrm{wt} . \% \mathrm{C} 14-\mathrm{Ti}_{0.65} \mathrm{Zr}_{0.35}(\mathrm{Mn}, \mathrm{Cr}, \mathrm{Fe}, \mathrm{Ni})_{2}$ + 10wt.\% La $\mathrm{La}_{0.8} \mathrm{Ce}_{0.2} \mathrm{Ni}_{5}$ used in the $\mathrm{H}_{2}$ compressor.

Figure 19. Front (top) and side (bottom) views of the $\mathrm{MH}$ compressor without sidewalls. The unit dimensions $(\mathrm{mm})$ are: $2465(\mathrm{~L}) \times 1350(\mathrm{~W}) \times 1325(\mathrm{H})$.

Figure 20. Conceptual configuration for an on-site hydrogen production / backup solution to support industrial applications based on thermal hydrogen compression.

Figure 21. Simplified layout (left) and general view (right) of hydrogen refuelling station with $\mathrm{MH}$ compressor developed by SAIAMC / UWC for Impala Platinum Ltd. (South Africa). 